\title{
Hyponatremic Mineralocorticoid Resistance due to Mineralocorticoid Receptor Defect
}

National Cancer Institute

\section{Source}

National Cancer Institute. Hyponatremic Mineralocorticoid Resistance due to

Mineralocorticoid Receptor Defect. NCI Thesaurus. Code C126810.

An autosomal dominant condition presenting with hyponatremia and hyperkalemia, mimicking low concentrations of aldosterone, associated with loss-of-function mutation(s) in the NR3C2 gene, encoding the mineralocorticoid receptor. 